\title{
Gender and Modes of Collaboration in Engineering: Technical Communication as a Social Process
}

\author{
Sandra Ingram \\ University of Manitoba ${ }^{1}$
}

This article explores collaborative writing as a social process, drawing attention to the role of gender in influencing shared-document writing. Research from the fields of sociology, linguistics, and communications points to contrasting patterns concerning how men and women approach collaborative tasks. Yet, significantly less attention has focused on how these gender-based styles of interaction intersect with broader structural forces. Technical communication courses in Engineering are ideal sites to examine the interplay between interaction and structure, due to the pervasivenes of an historically dominant male culture. An increased use of microethnographic studies in the classroom is recommended in order to enhance this dual understanding of the collaborative process. Pedagogical implications are drawn regarding the importance of viewing gender as both a structural and interactional influence on modes of collaboration.

COLLABORATIVE WRITING IS A FREQUENT ACTIVITY in the workplace. According to Duin (1991), recent studies indicate that engineers and other professionals spend as much as $30 \%$ of their time working with the writing of others (p. 26). In addition, there tends to be a strong relationship between the goals of collaborative writers and the needs of the organisations in which they work. Typically, collaborative writing groups are formed to solve problems, and they are charged with framing their solution in the form of a written document such as a book, article, proposal, or position paper (Morgan and Murray, 1991). As a result, in order to be understood, such groups must employ the vocabulary, knowledge, and beliefs shared by other members of the organisation. Winsor (1989) argues that collaborative writers

1 This article forms the basis for a pilot study conducted in the Faculty of Engineering, University of Manitoba during the fall of 1997 
must, therefore, have a good understanding of and form part of the organisational culture:

Writing at work is firmly embedded in a social web... This social network is most visible in organizations like workplaces or academic disciplines where actions are aimed at a collective goal. Within these organizations, writing is visibly used not just to record decisions and events, but to do the organization's work, to build its shared understanding, and to construct its knowledge (p. 271).

Successful writing teams may be linked even further to the survival and competitiveness of North American businesses in the 1990s. "Leading management thinkers believe that corporations and the people who work for them must increasingly cooperate and collaborate to survive" (Byrne, quoted in Roever and Mullen, 1994, p. 463). This emphasis on teamwork and writing within industry supports the rationale behind the establishment of collaborative writing programs in many professional faculties. Lipson (1988), argues that a major part of the socialization of professionals is learning the values, norms of behavior, and distinctive types of discourse associated with a given profession. She describes professions as structured, social units that share a common understanding as to appropriate forms of conduct. Embedded within these forms of conduct are specific conventions for thinking, interacting, and writing, which students must learn in order to become competent members of the professions they have chosen. For students who have selected professions which are collaboratively based, acquiring the norms and conventions surrounding the collaborative process helps them to become "communicatively competent" once they assume professional status (Bogdanowicz, 1987, p. 1).

Although subject to numerous definitions and interpretations, it is generally agreed that in its broadest sense collaborative writing refers to a variety of interactive writing experiences. Central to this understanding is the recognition that in the collaborative method, reading and writing are social rather than solitary, individual acts. The definitions of collaborative learning put forth by both Bruffee (1981, p. 107) and Wiener (1986, p. 54 55) imply that the key to this kind of activity is "consensus," or a process of "intellectual negotiation," which leads to "joint decisions," "collective judgments in groups," and shared authority over the writing process and product. Similarly, Allen et al. (1987) operationalize the concept by defining 
it as a process that "involves collaborators producing a shared document, engaging in substantive interaction about that document, and sharing decision-making power and responsibility for it" (p. 70). Cooper's (1989) ecological model of writing offers a dialectical interpretation of collaborative writing, by emphasizing that the characteristics of a piece of collaborative writing both determine and are determined by the characteristics of the writers and their interactions within the social context of the collaboration. The ecological model takes a systems-view towards the writing process, and suggests the metaphor of a web in that "anything which affects one strand of the web vibrates throughout the whole" (p. 9).

Each of these definitions of collaboration places an emphasis on the social nature of writing, and the extent to which the shape of the final written product is influenced by interactive processes. Thus, although a single shared document is made up of a series of recursive activities, which a group works together on, these activities are constructed within the social context of collaboration. For example, brainstorming, audience analysis, organisation, drafting, editing, and revising are all critical components of the collaborative writing process. Yet, these activities are accomplished through the interaction of group members, and thus, are socially constructed (Duin, 1991; Blyler, 1993).

Collaborative writing then, refers to more than simply a shared effort to produce a single document. In addition to producing collaboratively written material, those who participate in this form of writing, such as students in professional faculties, gain social knowledge relevant to their careers. For example, students become conversant with such collaborative social processes as working on a team, convening and participating in meetings, and giving and receiving constructive criticism (Roever and Mullen, 1994). All of these processes are essential to becoming communicatively competent once on the job.

My purpose in this article is to draw attention, not only to the interactional processes involved in shared-document writing, but also to structural forces that permeate the collaborative task. While increasing attention is being paid to the impact of gender-based styles of communication on the collaborative writing process, there is an insufficient attempt to link these patterns to a broader understanding of the role of gender as a structural force in influencing interactional styles and, hence, modes of collaboration. Through a literature review grounded largely within the sociology of education, this article attempts to shed light on how the 
collaborative process students take part in through technical communication courses in engineering is shaped by the operation of both structural and interactional processes. Finally, I contend that through increased microethnographic studies, classrooms and workplaces alike will be better informed by an understanding of how structural forces and interactional processes play themselves out to affect collaborative outcomes among men and women.

\section{Collaborative Writing as a Social Process: The Influence of Structural Forces}

Beyond the fact that collaborative writing requires a significant amount of shared interaction, decision-making, and responsibility to be successful, much remains to be understood about this complex activity. Collaboration as a social process has only recently come under study in such fields as sociology, linguistics, and communications. The examination of any phenomenon as a social process implies gaining a greater understanding of the societal forces or constraints which shape it. These forces are inherent in the structure of a society and provide the organisational basis for power relations based on such factors as race, social class, and gender (Giddens, 1984).

The issue of structural forces is of particular concern in a classroom context, where students are exposed to a prevailing set of power relations and are largely expected to conform to certain behavioral standards (Bowles and Gintis, 1976). Within the sociology of education, significant attention is paid to understanding the social processes that take place within schools, and the extent to which these processes are linked to factors which originate outside the classroom. One particular approach, which has been advanced in recent years, emphasizes the primarily conservative role schools play in society and the means by which they function largely to perpetuate existing power relations. This school of thought, referred to as social reproduction theory, argues that schools function, at least in part, as a means of reproduction by basically reflecting the values, behaviors, and language of the dominant culture (McLaren, 1989; Aronowitz and Giroux, 1985). The dominant culture refers to those groups within society who have traditionally held the greatest economic, political, and social power. Social reproductionists argue that as a result of their control over economic conditions, the dominant culture is able to exert a similar form of control over the schooling process. This hegemony is reflected in the class character 
of the school, whereby children of various social classes are taught the personality and dispositional traits they will require later on when they join the labour force. During the schooling process, then, students from different societal groups are provided with the knowledge and skills they need to occupy their respective places in a labour force which is stratified, not only along class lines, but also according to race and gender (Giroux, 1983).

Social reproduction theory has yielded important insights into the structural basis of workplace behaviours and status (Bowles and Gintis, 1976). Such theorists argue that structures have operated historically to limit the participation of women and minorities in the work force to lowstatus jobs and to reproduce behaviors and attitudes consistent with those positions. Many professions, such as engineering, remained closed to women for decades, due primarily to the fact that women did not form part of the initial organisational or power structure (McIlwee and Robinson, 1992). As a result, their lack of representation in determining the knowledge base and standards for such professions effectively excluded women from pursuing higher-status job opportunities.

Both engineering and engineering education have come to be described as androcentric, not only due to the structural exclusion of women from the profession historically, but also due to the masculine culture which has arisen in the field over time (Carter and Kirkup, 1990; Hacker et al., 1990). This emphasis on culture as a constraint to the inclusion of women in engineering can be better understood by examining another approach, which forms part of the reproductionist school of thought. Referred to as cultural reproduction theory, this framework enhances the insight gained from an analysis of structural forces to provide a more comprehensive understanding of the manner in which women's experiences are incorporated, not only within the profession of engineering, but also in the engineering classroom and the collaborative writing processes that take place within it.

Cultural reproduction theorists, in contrast to social reproductionists, are more concerned with the broader realm of culture and the ways in which schools tend to reproduce the forms of knowledge, values, language, and modes of style that constitute the dominant culture and its interests (Giroux, 1983). Thus, while social reproductionists argue that students are sorted and stratified in schools based on their background characteristics and the relative value placed on these characteristics in the larger society 
and workplace, cultural reproductionists stress that schools are cultural institutions, functioning to create and recreate an effective dominant culture through the teaching of norms, values, and dispositions.

Central to the cultural reproduction argument is the notion of "cultural capital," first formulated by French sociologist Pierre Bourdieu (Bourdieu and Passeron, 1977). Cultural capital refers to the different sets of cultural and linguistic competencies that individuals learn by way of socialization, and which are influenced by the class location and other aspects of the social position of their family. These competencies are assigned certain social values and status in accordance with what the dominant class labels as the most valued cultural capital. Hence, like economic capital, cultural capital tends to be controlled by, and serve, the interests of the most powerful class in society. Therefore, the possession of valued cultural capital may be seen as largely influential in affecting an individual's educational and occupational fate within society (Giroux, 1983). Schools are seen as part of a larger universe of symbolic institutions that do not overtly impose docility and oppression, but reproduce existing power relations more subtly through the production and distribution of a dominant culture that tacitly confirms what it means to be educated (Aronowitz and Giroux, 1985).

Thus, with their complementary emphases as to the mechanisms of educational stratification, both social and cultural reproduction theorists put forth a strong relationship between the places individuals occupy in the social structure and the degree to which they achieve social mobility. Both schools of thought focus on the ways in which larger forms of economic and social inequalities are linked to patterns of educational inequality and the degree to which these patterns affect the educational and occupational fate of individuals.

\section{"Macro" and "Micro" Approaches to the Analysis of Social Phenomena}

The emphasis reproduction theorists place on analysing the relationship between social structure, and patterns of educational, and occupational mobility is generally seen as indicative of a macro-sociological approach, that is, an approach in which large-scale structural processes, such as gender, are believed to be significant in accounting for the existence of particular social phenomena (Mehan et al., 1986).

Reproductionists have often been criticised for their failure to address 
the specific means by which so-called macro-structural forms are reproduced in the educational system. Although these theorists claim that students are sorted and stratified on the basis of background characteristics such that differential opportunities are made available to them, they neglect to specify exactly how this process occurs. Furthermore, critics question the perception reproduction theorists have of the social structure as a stable and static entity which does not take account of the importance of smaller, moment-by-moment occurrences in students' patterns of educational mobility (Mehan et al., 1986). Finally, reproductionists have been criticised for the extent to which they emphasize the idea of determination in their analyses to the point of offering little hope for social change and even less reason for developing alternative educational practices. By downplaying the importance of human agency, reproduction theorists are said to offer almost no hope for challenging and changing the repressive features of schooling (Aronowitz and Giroux, 1985).

A school of thought exists within sociology which encompasses these concerns and offers a different interpretation for the explanation of social phenomena. Referred to as the school of symbolic interactionism, this tradition postulates that members of society are active participants in the contexts in which they behave. Primarily through the process of face-toface interaction, they negotiate each other's definition of the situation and work to construct their environment, rather than simply responding to it. Thus, "symbolic interactionism sees meaning as social products, as creations that are formed in and through the defining activities of people as they interact" (Blumer, 1969, p. 5).

Microethnography is the research technique most often associated with the symbolic interactionist perspective. Ethnography may be described as the following:

A holistic, thick description of the interactive processes involving the discovery of important and recurring variables in the society as they relate to one another under specified conditions, and as they affect or produce certain results and outcomes in the society (Lutz, 1981, p.52).

The ethnographic or qualitative approach emphasizes the researcher's role in observation and interpretation of the subjective states of individuals. The researcher attempts to understand the subject's definition of the situation and examine how the world is experienced from his or her own frame of reference (Schwartz and Jacobs, 1979). Ethnography involves the 
use of many techniques including observation, interviews, the study of historical records and current public documents, and use of demographic data (Lutz, 1981).

The term "micro" refers to a particular emphasis in the ethnographic tradition on the minute details of face-to-face interaction as a means by which events are socially constructed and organized. The theory, which informs microethnography, is concerned with the ways in which individuals' identities, and in many cases, their patterns of social and educational mobility are assembled through the process of social interaction. This approach to the analysis of social phenomena is referred to as "microsociological"(Mehan, 1987).

Hence, while micro-sociologists may agree with the assertion that students are sorted and stratified within the educational system in a manner which makes differential opportunities available to them, they would disagree that students' futures are predetermined by their social class, race, or gender location in the social structure. They would argue, in contrast, that it is the accumulated effects of specific interactional events which contribute to the creation of an educational and occupational stratification system (Mehan, 1987).

\section{Gender and Modes of Collaboration: A Combination of Structural and Interactional Forces}

A synthesis of both macro and micro approaches to the analysis of social phenomena provides a powerful model in which to examine the influence of gender on modes of collaboration. Thus, while organisational structures and the power relations which result from them are important in an analysis of gender, interactional styles play a significant role as well. Both the impact of large-scale social processes and the immediacy of faceto-face interactions can effectively be combined in order to understand the role gender plays in the collaborative process. More specifically, by focusing on specific interactional events that take place among male and female students as they work towards achieving collaborative goals, it may be possible to demonstrate that certain 'distal' circumstances, or those that originate outside student teams, interact with more 'proximal' or local circumstances to influence the collaborative process. Previous discussions of women in nontraditional occupations have tended to choose one side or the other of this dialectic. A more complete explanation, however, lies in the intersection of the two (McIlwee and Robinson, 1992). 
For example, although gender has received an increased share of attention more recently regarding its potential impact on the collaborative process, there lacks among scholarly interpretations an attempt to link together various theoretical categories into a larger, more explanatory framework. Lay (1993) acknowledges the role played by external factors in influencing modes of collaboration based on gender, yet her work is primarily grounded in contrasting socialization patterns, and the influence of psychological and familial roots in determining communicative behavior among men and women. Gilligan (1982), Lyons (1983), and other feminist scholars lay the foundation for the argument by asserting that based on different patterns of socialization, men and women understand and define relationships in different ways, thereby affecting the manner in which they approach others. "Women, because of their identity with the primary nurturer within the family, are often experts at initiating and maintaining relationships, on acknowledging and preserving community" (Lay, 1992, p. 84-85). As a result, women are believed to approach relationships with a concern and responsiveness to others, exhibiting an "ethic of care." Men, in contrast, have been socialized from an early age to establish a sense of separation and distinction, both through the traditional family structure and the educational system (Lay, 1994, p. 63). Consequently, their approach to relationships is said to reflect an "ethic of objectivity," which is based on impartiality, objectivity, and the distancing of the self from others (Lyons, 1983, p. 134).

Lay (1993) argues that students enter the post-secondary writing classroom with a set of gendered identities, built up through different socialization patterns as male and female children, that are then reinforced through the school system. Such contrasting patterns of socialization have been linked to substantial differences in the ways in which men and women interact in various settings, including the professional communications classroom. For example, because women place an emphasis on connections in their relationships, they tend to view interaction as a means of sharing and a way to keep relations intact. Thus, women make use of such communicative strategies as active listening, posing questions, and soliciting input from others in order to make decisions, which are often based on consensus (Lay, 1989).

This contrasts sharply with a male view on the goals of interaction. Lay (1989) points to findings from various studies that have been supported more recently by Tannen $(1990 ; 1994)$ suggesting that because the male 
approach to relationships is more authoritative and competitive, interaction is used primarily as a means of maintaining or gaining status. Thus, it is characteristic for men to command attention verbally through such methods as giving direction, lecturing their audience, interrupting, and taking longer and more frequent turns in conversations.

Ede and Lunsfords' (1990) extensive study of collaborative writing practices within professional organisations strengthens this argument by asserting that gender differences may, in turn, influence patterns of cooperation. These authors provide categories that are potentially useful in the description of gendered collaboration by distinguishing between hierarchical and dialogic modes. The hierarchical mode is characterised by a goal driven approach to writing that is strongly focused on problem resolution and the efficient realisation of a particular end product. Individuals within the hierarchical writing team play clearly defined and structured roles, giving rise to carefully and often rigidly structured documentation. Ede and Lunsford found the hierarchical mode of collaboration to be the dominant means of producing texts in the professions they studied. It was also the most commonly used style among men and, as a result, is referred to as a masculine mode of discourse (p. 133).

A significantly less widespread mode of collaboration was also identified in Ede and Lunsfords' investigation. Referred to as a dialogic mode of collaboration, this form is more loosely structured and flexible in that an individual may occupy multiple or shifting roles as a project progresses. Also in this mode, the process of identifying and defining goals is often as important as the goals themselves and sometimes even more important. In dialogic collaboration, the group dynamic is seen as an essential part of the process and as a means of individual satisfaction with the group. Ede and Lunsford refer to the dialogic mode of collaboration as predominantly feminine, as most of the respondents who described their participation in this form of shared document writing were female (p. 133).

The modes of collaboration identified by Ede and Lunsford greatly enrich the understanding of gender and the collaborative process, and have since been utilised in studies conducted on the engineering classroom (Flynn et. al., 1991). Nonetheless, this approach, derived largely from research and theory in composition, does not take into account the structural or cultural contexts in which modes of collaboration are situated. Similarly, an operational definition of the concept of collaboration which breaks it up into concrete and observable components is needed for a more thorough 
understanding of precisely what it means to collaborate, as well as how various modes can arise. What is lacking is a theoretical model which encompasses all stages in the process, beginning with the structural basis from which men and women approach collaborative tasks, to the cultural and interactive styles that arise, to resulting modes of collaboration.

An explanatory framework which links structure and interactional styles to the examination of gender adds significant insight, particularly in relation to understanding modes of collaboration within the technical communication classroom in engineering. Within this model, the concept of culture plays a central role, in that it represents a point of convergence for both structural and interactional processes. Culture has been described by McIlwee and Robinson (1992) as a force that manifests itself through day-to-day activities and interactions:

Culture lies largely in the rituals of conformity: the forms of talk, styles of interaction, and modes of dress that signal our belief in it. Culture in this sense, is a form of "impression management:" we act in such a way as to create an impression in others that we are adhering to a set of values (p. 17).

Various verbal and non-verbal interactional styles can thus be seen as indicative of cultural adherence and form part of a repertoire of shared conventions.

An understanding of a culture, however, is incomplete without a corresponding knowledge of the relations of power which provide its foundation. Thus, in describing a culture's values, norms, and styles of discourse, one must also examine how it is a function of larger relations of domination (McIlwee and Robinson, 1992). Engineering and engineering education have come to be identified as symbolic of a masculine culture, not only because of the pervasiveness of masculine values and interactional styles, but also due to the male-dominated structure which supports it.

McIlwee and Robinson utilise an explanatory framework in their analysis of the career development and status of women in engineering, which encompasses all three forces: structural, interactional, and cultural. Their study, based on the use of questionnaires and in-depth interviews, followed women engineers through their university, workplace, and family relationships to explore their experiences regarding the entry of women into the profession. Their data reveal that women engineers are more likely 
to succeed in some workplaces than others, despite the fact that all are male-dominated. They suggest that in organisations where engineers as a group are powerful, they are able to define workplace culture in a strongly male-dominated way, and the "culture of engineering" is more firmly entrenched.

The culture of engineering:

Stresses the centrality of technology to the workplace, and therefore the importance of engineers as producers of that technology. This culture is the means by which engineers attempt to inflate the importance of the "cultural capital" that only they hold. It is the ideology through which they pursue organizational power and influence (1992, p. 20).

In these settings, workplace culture takes on a form strongly identified with the male gender role, emphasizing aggressive interactional displays of technical ability, self-confidence, and impression management. The ability of men to conform to this culture is enhanced by a gender socialization pattern that encourages 'tinkering' and allows them to be more comfortable with the hands-on aspects of engineering. Thus, McIlwee and Robinson assert "it is not necessarily that men are better engineers, but they are better at appearing to be better engineers" (1992, p.91). Examples of organisations where engineers as a group hold more power include the highly technical, and more autonomous research and development firms. In such settings, women's inability to conform to the male-defined culture of the workplace contributes to their subordinate status, and their careers suffer.

In contrast, McIlwee and Robinson found that in organisations where engineers hold less power, women face fewer obstacles in terms of confronting a male-defined professional culture. "Women tend to succeed in larger, more bureaucratically structured organizations that evaluate engineers on the basis of formal qualifications and achievements, provide special resources for women and limit the power of engineers" (p. 182). These structural or organisational differences tend to mitigate the influence of a male-dominated culture and its corresponding interactional displays, thereby improving women's chances of success and promotion. 


\section{Modes of Collaboration in Engineering Education: The Role of Technical Communication in Reproducing Gender Relations}

An increased number of studies, which use a comprehensive approach to gender issues, such as that put forth by McIlwee and Robinson, are needed to increase our understanding of women in engineering. Because faculties of engineering are structured similarly to the workplace, at least in terms of male-female ratios among students and academic staff, numerous opportunities exist to examine the experiences of women as they navigate their way through what remains a largely androcentric field.

Technical communication provides an ideal environment in which to examine the interplay between structural forces and interactional styles based on gender. Technical communication courses are intended to provide students with the communication skills needed to assimilate, evaluate, translate, and make complex information useful (Barabas, 1990). In engineering faculties, technical communication courses "help engineering students understand the professional context in which they will later work; as professionals, they will solve technical problems and then communicate the solutions to those who need them" (Parker,1990, p. 95).

Most technical communication courses offered in engineering schools include a collaborative component, in which students work together towards the production of a shared document, and then receive a mark based on the success of their cooperative efforts. The structure of this activity is intended to prepare students for the kind of setting they will encounter in their careers, where working and writing with others is a reality (Gilbertsen and Killingsworth, 1990). Thus, through technical communication, students become familiar not only with how to communicate the results of their problem-solving efforts to a broader audience, but also the interpersonal skills necessary to work as part of a team.

If, as McIlwee and Robinson (1992) suggest, both structural and interactional forces play a prominent role in affecting the experiences of women in the field of engineering, the collaborative writing process must also come under scrutiny for its potential role in reproducing gender relations. The structure of writing teams, as well as male and female differences in interactional style, have the capacity to affect virtually every stage of the collaborative process, ranging from brainstorming and audience 
analysis, to planning, organization, writing, and revision processes. The extent to which gender-based interactional styles are found and linked to a male-dominated culture may impact upon resulting modes of collaboration. The major components of collaboration as defined by Allen et al. (1987)interaction, decision-making, and responsibility-could provide a useful framework within which to observe and document the influence of broader and more large-scale processes.

Since technical communication is a course which emphasizes a more collaborative approach to learning than many engineering courses, the obstacles to women's participation may be lessened by the mechanisms built into the course, which encourage and reward cooperative behavior. Cooperative behavior, as discussed earlier, has been shown by some theorists to be more compatible with feminine modes of interaction. On the other hand, cooperative learning situations may function as double-edged swords for women in that they can also become sites for male students to exert their more aggressive interactional style, resulting in the devaluation of women's contributions (Felder et al., 1995). An increased number of microethnographic studies which make use not only of interviews and survey data, but also observations of collaborative writing teams at work would yield considerable insight into technical communication itself as a social process.

\section{Pedagogical Issues}

Further research into the technical communication classroom in engineering as a potential site for the reproduction of gender relations has pedagogical, as well as theoretical significance. Explanatory frameworks derived from such research can sensitize instructors to several issues which potentially affect both course delivery and classroom climate. For example, although reproduction theory has been most directly applied to the role of public schools in society, it nonetheless draws attention to the impact of both structural forces and cultural norms in all formal educational settings, and the degree to which patterned social behaviour is influenced by power relations. Similarly, the school of symbolic interactionism, through its emphasis on the role of smaller scale, face-to-face interactions highlights the creative tension inherent in the educational process, and the extent to which individual patterns of educational mobility are assembled through the process of social interaction. 
An enhanced knowledge of how both macro and micro processes combine to shape educational outcomes can assist instructors in maximizing opportunities for women's participation in the classroom. Increased attention may be directed towards the possible constraints women face in confronting a male cultural and interactional climate during the process of shared-document construction. Such barriers could potentially affect the extent to which women fulfill their collaborative goals within the team as well as their level of participation in resulting documentation. The role of the instructor as part of the larger classroom climate may also fall under scrutiny. In order to work towards a more inclusive approach, instructors need to become sensitized to their teaching styles, methods of evaluation, and other practices that may require revision.

The emphasis which symbolic interactionists place on human agency allows for the possibility of social change and transformation to take place in settings such as the classroom, where entrenched power relations exist. It is this creative aspect of schooling that allows some scholars such as Lay (1993) and Thralls and Blyler (1993) to argue for the role of power relations to be exposed in the communications classroom, thus allowing students to challenge or resist the structural forces that influence their interactive behavior. Lay argues that instruction can then have an emancipatory effect on students, encouraging them to become active participants in the production of knowledge, rather than passive recipients in knowledge reproduction. She points further to the potential that exists in the communication classroom, not only to question existing relations of power that influence the construction of knowledge, but also to overturn entrenched patterns of interaction based on gender. Lay (1989) proposes that, in order for the collaborative writing process to achieve its full potential, men and women should be allowed the opportunity to leave behind their socially constructed identities and engage in the production rather than the mere reproduction of knowledge:

...by allowing a fuller range of behaviour to males, by incorporating within our definitions of masculinity such traits as nurturing, and by encouraging ultimately androgynous identity; we should allow men as well as women to be comfortable and effective collaborators... The effective collaborator, then, would have full access to the interpersonal tools we too often label masculine or feminine (p. 12). 
This approach, which draws attention to the potential for both educational reproduction and reform, is derived from a school of thought in the sociology of education known as critical theory or critical pedagogy. Critical theory runs contrary to the reproductionist view of schooling, in that it argues schools possess a creative function, and are capable of changing the structures of society which influence the distribution of economic power and cultural status (Kelly and Nihlen, 1982).

Regardless of the specific pedagogical approach instructors use to address the situation, it is generally agreed that the mere increase in the numbers of women entering technical communication classrooms in engineering does not mean an end to existing power relations or maledominated cultural and interactional styles. Minister (1991), provides this insight into the pervasiveness of established relations of power in the larger society:

The general public appearance of women as full-time wage earners at all levels of organizations and in all kinds of work, as full-time entrepreneurs and business owners, graduate students, students in professional schools, and holders of political office is so recent that it has had little effect upon the way women speak and the way in which persons in positions of power expect women to speak. Changes in gender presentation lag far behind societal changes (p. 29).

Technical communication classrooms thus represent opportunities to examine, not only how entrenched power relations and interactional styles play themselves out, but also the possibilities which exist for change. As both classrooms and organisations alike struggle to contend with the challenges of gender and cultural diversity, such knowledge can only serve to enhance our understanding of the collaborative process.

\section{References}

Allen, N., Atkinson, D., Morgan, M., Moore, T., \& Snow, C. (1987). What Experienced Collaborators Say about Collaborative Writing.Journal of Business and Technical Communication, 2(1), 70-90. 
Aronowitz, S., \& Giroux, H. (1985). Education Under Seige: The Conservative, Liberal and Radical Debate Over Schooling. London: Routledge and Kegan Paul.

Barabas, C. (1990). Technical Writing in a Corporate Culture: A Study of the Nature of Information. Norwood, NJ: Ablex Publishing Corporation.

Blumer, H. (1969). Symbolic Interactionism: Perspective and Method. Englewood Cliffs, N.J.: Prentice-Hall, Inc.

Blyler, N.R. (1993). Theory and Curriculum: Reexamining the Curricular Separation of Business and Technical Communication. Journal of Business and Technical Communication, 7(2), 218-245.

Bogdanowicz, M. (1987). Communicative Competence: Business Savvy and the Technical Writer. Technostyle, 6(1), 1-5.

Bourdieu, P., \& Passeron, J. (1977). Reproduction in Education, Society and Culture. London: Sage.

Bowles, S., \& Gintis, H. (1976). Schooling in Capitalist America. New York: Basic Books.

Bruffee, K. (1981). The Structure of Knowledge and the Future of Liberal Education. Liberal Education, 67(1), 177-186.

Carter, R., \& Kirkup, G. (1990). Women In Engineering: A Good Place to be?. London: Macmillan Education, Ltd.

Cooper, M. (1989). The Ecology of Writing. In M. Cooper \& M. Holzman (Eds.), Writing as Social Action, (pp. 1-13). Portsmouth, NH: Boynton/ Cook.

Duin, A.H. (1991). Computer-Supported Collaborative Writing: The Workplace and the Writing Classroom. Journal of Business and Technical Communication, 5(2), 123-150.

Ede, L., \& Lunsford, A. (1990). Singular Texts/Plural Authors. Southern Illinois University Press.

Felder, R., Felder, G., Mauney, M., Hamrin, C., \& Dietz, J. (1995). A Longitudinal Study of Engineering Student Performance and Retention: Gender Differences in Student Performance and Attitudes. Journal of Engineering Education, 84(2), 151-163. 
Flynn, E., Savage, G., Pentik M., Brown, C., \& Watke, S. (1991). Gender and Modes of Collaboration in a Chemical Engineering Design Course. Journal of Business and Technical Communication. 5(4), 444-461.

Giddens, A. (1984). The Constitution of Society. Berkeley: University of California Press.

Gilligan, C. (1982). In a Different Voice: Psychological Theory and Women's Development. Cambridge: Harvard University Press.

Gilbertson, M., \& Killingsworth, M. (1990). Behavioral Talk-Write as a Method of Teaching Technical Editing. Journal of Business and Technical Communication, 1(1), 108-114.

Giroux, H. (1983). Theories of Reproduction and Resistance in the New Sociology of Education. Harvard Educational Review, 53(3), 257-93.

Hacker, S., Smith, D., \& Turner, S.(Eds.) (1990). Doing it the Hard Way: Investigations of Gender and Technology. Boston: Unwin Hyman.

Kelly, G. \& Nihlen, A. (1982). Schooling and the Reproduction of Patriarchy: Unequal Workloads, Unequal Rewards. In M. Apple (Ed.), Cultural and Economic Reproduction in Education: Essays on Class, Ideology and the State. London: Routledge and Kegan Paul.

Lay, M. (1993). Gender Studies: Implications for the Professional Communication Classroom. In N. Roundy Blyler \& C. Thralls (Eds.), Professional Communication:The Social Perspective, (pp. 215-229). Newbury Park: Sage Publications.

Lay, M. (1989). Interpersonal Conflict in Collaborative Writing: What We Can Learn From Gender Studies. Journal of Business and Technical Communication, 3(2), 5-28.

Lay, M. (1994). The Value of Gender Studies to Professional Communication Research. Joumal of Business and Technical Communication, 8(1), 58-90.

Lay, M. (1992). The Androgynous Collaborator: The Impact of Gender Studies on Collaboration. In J. Forman Portsmouth (Ed.), New Visions of Collaborative Writing, (pp. 82-104). NH: Boynton/Cook-Heinemann.

Lipson, C. (1988). A Social View of Technical Writing. Journal of Business and Technical Communication. 2(1), 7-20. 
Lutz, F. (1981). Ethnography-The Holistic Approach to Understanding Schooling. In J. Green \& C. Wallat (Eds.), Ethnography and Language in Educational Settings, (pp. 51-63). Norwood, N.J.:Ablex Publishing Corporation.

Lyons, N. (1983). Two Perspectives: On Self, Relationships, and Morality. Harvard Educational Review. 53(2), 125-145.

McIlwee, J.S., \& Robinson, J.G. (1992). Women in Engineering: Gender, Power and Workplace Culture. Albany: SUNY Press.

McLaren, P. (1989). Life In Schools: An Introduction to Critical Pedagogy in the Foundations of Education. New York: Longman Inc.

Mehan, H., Hertweck, A., \& Meihls, J. (1986). Handicapping the Handicapped: Decision-Making in Students' Educational Careers. Stanford: Stanford University Press.

Mehan, H. (1987). Language and Power in Organizational Process. Discourse Processes, 10, 291-301.

Minister, K. (1991). A Feminist Frame for the Oral History Interview. In S. Berger Gluck \& D. Patai (Eds.), Women's Words: The Feminist Practice of Oral History, (pp. 27-41). New York: Routledge.

Morgan, M., \& Murray, M. (1991). Insight and Collaborative Writing. In M. Lay \& W. Karis (Eds.), Collaborative Writing in Industry: Investigations in Theory and Practice, (pp. 64-71). New York: Baywood Publishing Co.

Parker, A. (1990). Problem-Solving Applied to Teaching Technical Writing. The Technical Writing Teacher, 17(2), 95-103.

Roever, C., \& Mullen, D. (1994). Teamwork: Preparing Students for the New Reality. Joumal of Business and Technical Communication 8(4), $462-$ 474.

Schwartz, H., \& Jacobs, J. (1979). Qualitative Sociology: A Method to the Madness. New York: The Free Press.

Tannen, D. (1990). You Just Don't Understand: Women and Men in Conversation. New York: William Morrow, Ballantine. 
Tannen, D. (1994). Talking From Nine to Five: How Women's and Men's conversational Styles Affect Who Gets Heard, Who Gets Credit, and What Gets Done at Work. New York: William Morrow and Company, Inc.

Thralls, C. \& Blyler, N. (1993). The Social Perspective and Pedagogy in Technical Communication. Technical Communication Quarterly, 2(3), 249-267.

Weiner, H. (1986). Collaborative Learning in the Classroom: A Guide to Evaluation. College English, 48, 52-61.

Winsor, D. (1989). An Engineer's Writing and the Corporate Construction of Knowledge. Written Communication, 6(3), 270-85. 